\title{
Editorial
}

\section{Titanium and Its Alloys for Biomedical Applications}

\author{
Hyun-Do Jung 1,2 \\ 1 Department of Biomedical-Chemical Engineering, Catholic University of Korea, Bucheon 14662, Korea; \\ hdjung@catholic.ac.kr \\ 2 Department of Biotechnology, The Catholic University of Korea, Bucheon 14662, Korea
}

Citation: Jung, H.-D. Titanium and Its Alloys for Biomedical Applications. Metals 2021, 11, 1945. https://doi.org/10.3390/ met11121945

Received: 21 November 2021 Accepted: 26 November 2021 Published: 2 December 2021

Publisher's Note: MDPI stays neutral with regard to jurisdictional claims in published maps and institutional affiliations.

Copyright: (C) 2021 by the author. Licensee MDPI, Basel, Switzerland. This article is an open access article distributed under the terms and conditions of the Creative Commons Attribution (CC BY) license (https:// creativecommons.org/licenses/by/ $4.0 /)$.

\section{Introduction and Scope}

In the past decades, metals have been considered as promising materials in the fields of regenerative medicine and tissue engineering. Metallic bio-materials with excellent mechanical strength can effectively support and replace damaged tissue. Hence, metals have been widely used in load-bearing applications for dentistry and orthopedics. cobalt-, iron-, and titanium (Ti)-based alloys are representative bio-metals used in various forms such as vascular stents, hip joints, dental, and orthopedic implants. However, the alloying elements of $\mathrm{Co}$ - and $\mathrm{Fe}$-based alloys, $\mathrm{Co}, \mathrm{Ni}$, and $\mathrm{Cr}$, induce severe toxicity when ionized in the body, which limits their clinical use.

On the other hand, Ti and its alloys have been widely used as medical devices and implants applied in dental and orthopedic applications due to their excellent bone regeneration ability, mechanical properties, and corrosion resistance. Even though Ti and its alloys have been generally used for biomedical applications, there are still challenges that must be met in order to satisfy clinical applications. For example, osseointegration with the surrounding bone tissue at the initial stage of implantation has been pointed out as a major issue. In recent years, much attention has been placed on the design of new Ti alloys and composites with a modified process such as the advanced casting method and artificial intelligence for fabricating dental and orthopedic implants with lower elastic moduli in combination with higher strength. On the other hand, some researchers have focused on the surface modification of Ti-based medical devices and implants for inducing rapid bone ingrowth.

This Special Issue, "Titanium and Its Alloys for Biomedical Applications", has been proposed as a means to present recent developments in biomedical applications. The nine research articles included in this Special Issue cover broad aspects of Ti-based alloys and composites with respect to their composition, mechanical, and biological properties, as highlighted in this editorial.

\section{Contributions}

\subsection{Surface Modification}

Four papers in this section concern the surface modification of Ti and its alloys, including the final developmental stage of medical devices and surface treatment of implants.

Kim et al. studied the ultraprecision magnetic abrasive finishing (UPMAF) of a nickel (Ni)-Ti stent wire using ecofriendly oil [1]. Generally, the accuracy and precision of Ni-Ti stent wire sizes are important factors in the clinical field as well as toxicity of the stent surface. Therefore, in this study, a UPMAF process with earth-friendly olive and castor oil was investigated. Using both olive and castor oil, the surface roughness was modified without any change of components of original Ni-Ti metal compared to using industrial light oil.

Kim et al. compared and analyzed various Ti surface treatment technologies for the orthopedic field [2]. They applied hydroxyapatite (HA) blasting, sand blasting and an acid-etching (SLA) process on a Ti substrate. Additionally, other anodic oxidation (AO) 
and micro-arc oxidation (MAO) processes were conducted on the SLA-treated Ti. A $\mathrm{TiO}_{2}$ layer created by the $\mathrm{AO}$ and $\mathrm{MAO}$ processes increased porosity and surface roughness and consequently enhanced cellular responses.

Huang et al. used high-power impulse magnetron sputtering to deposit tantalum oxide and $\mathrm{Ta}(\mathrm{Zn}) \mathrm{O}$ thin films on porous Ti prepared by plasma electrolytic oxidation [3]. The surface showed antibacterial properties with Staphylococcus aureus and Actinobacillus actinomycetemcomitans bacterias and improved cellular activities in terms of the adhesion, migration, and proliferation of osteoblastic cells.

Oh et al. used electrophoretic deposition to modify the Ti surface and layered graphene oxide-based coatings that control drug loading and release by varying the thickness of the coating layer [4]. The coatings enhanced surface hydrophilicity and hardness as well as bone differentiation properties when compared to the drug simply adsorbed to the surface.

\subsection{Alloys and Ti Matrix Composite}

The Ti alloys and Ti matrix composite were developed for use in the aerospace industries by enhancing mechanical properties and corrosion resistance. Despite this, it was revealed that such alloys can also find an excellent application field as biomaterials. Therefore, this section comprises three papers and concerns the manufacturing techniques of alloy and composite applied in bioengineering.

Jörg et al. fabricated a Ti6Al4V alloy that is extensively used in biomedical applications, using precision centrifugal casting [5]. The optimized centrifugal casting process of the Ti6Al4V provided a high-quality surface and equivalent biologic material quality as well as a reduction in cost for manufacturing.

Jha et al. used the CALPHAD and artificial intelligence for new Ti-based alloys [6]. They proposed an efficient approach for screening the compositions and process parameters that maximize the stability of $\beta$ phase while minimizing $\alpha$ " and $\omega$-phase formations on $\mathrm{Ti}-\mathrm{Zr}-\mathrm{Nb}-\mathrm{Sn}$ systems. In order to accelerate the development process, AI algorithms were used to predict alloys that are expected to meet the requirements with the phase stability of $\beta$ phase.

Ti-matrix composites using bone were produced by Jeong et al. [7]. Ball-milled Ti6Al4V powders and equine bone (EB) powders were spark plasma sintered at $1000{ }^{\circ} \mathrm{C}$. The existence of hydroxyapatite, the main component of EB, in a sintered Ti6Al4V matrix increased the hardness of composites, indicating good mechanical properties.

\subsection{Advanced Analysis}

The characterization and evaluation of Ti alloys have also attracted significant attention to keep up with development speed of Ti-manufacturing technologies. Two papers discussed advanced analysis methods for mechanical and biological properties

There have been many efforts to fabricate Ti alloys with a low elastic modulus to reduce stress-shielding effects that deteriorate the bone healing. Meng et al. investigated the deformation behavior of a Ti36Nb5Zr alloy with a $\beta$ phase using in situ synchrotron $X$-ray diffraction (SXRD) [8]. They proved deformation mechanisms of $\beta$-type Ti alloys including elastic and plastic deformations.

Beltrán et al. confirmed the potential of grade V Ti mini-transitional implants for a temporary overdenture [9]. Bone area fraction occupancy after in vivo test was analyzed by backscattered scanning electron microscopy (BS-SEM), and eventually it was demonstrated that grade $\mathrm{V} \mathrm{Ti}$ is an appropriate material for a dental implant.

\section{Conclusions and Outlook}

The present Special Issue of Metals presents an extensive insight into the state-of the-art of the research on developing Ti and its alloys for biomedical applications. The number of articles and the wide range of topics prove the continued interest in this group of materials. The development and progress in Ti and its alloys have played an important 
role in manufacturing medical devices and dental and orthopedic implants that are not possible with other metals.

As a guest editor of this Special Issue, I hope that these papers will be useful to researchers, designers, and engineers investigating in the development of advanced Ti alloys and improvement of their performance. Additionally, I am honored to be a guest editor and glad to report the success of this Special Issue. My sincere thanks to the reviewers and editors of Metals for their continuous support.

Funding: This work was supported by The Catholic University of Korea, Research Fund, 2021 and the National Research Foundation of Korea (NRF) grant funded by the Korea government (MSIT) (2021R1A2C1091301), the framework of international cooperation program managed by the National Research Foundation of Korea (2021K2A9A2A06037540), and Korean Fund for Regenerative Medicine funded by Ministry of Science and ICT, and Ministry of Health and Welfare (2021M3E5E5096420, Korea).

Conflicts of Interest: The author declare no conflict of interest.

\section{References}

1. Kim, J.S.; Nam, S.S.; Heng, L.; Kim, B.S.; Mun, S.D. Effect of environmentally friendly oil on Ni-Ti stent wire using ultraprecision magnetic abrasive finishing. Metals 2020, 10, 1309. [CrossRef]

2. Kim, J.; Lee, H.; Jang, T.-S.; Kim, D.; Yoon, C.-B.; Han, G.; Kim, H.-E.; Jung, H.-D. Characterization of Titanium Surface Modification Strategies for Osseointegration Enhancement. Metals 2021, 11, 618. [CrossRef]

3. Huang, H.-L.; Tsai, M.-T.; Chang, Y.-Y.; Lin, Y.-J.; Hsu, J.-T. Fabrication of a Novel Ta (Zn) O Thin Film on Titanium by Magnetron Sputtering and Plasma Electrolytic Oxidation for Cell Biocompatibilities and Antibacterial Applications. Metals 2020, 10, 649. [CrossRef]

4. Oh, J.-S.; Jang, J.-H.; Lee, E.-J. Electrophoretic Deposition of a Hybrid Graphene Oxide/Biomolecule Coating Facilitating Controllable Drug Loading and Release. Metals 2021, 11, 899. [CrossRef]

5. Jörg, F.; Betül, K.A.; Heiner, M.; Gerhard, K.; Erwin, B.R. Effects of Ti6Al4V Surfaces Manufactured through Precision Centrifugal Casting and Modified by Calcium and Phosphorus Ion Implantation on Human Osteoblasts. Metals 2020, 10, 1681. [CrossRef]

6. Jha, R.; Dulikravich, G.S. Discovery of new Ti-based alloys aimed at avoiding/minimizing formation of $\alpha^{\prime \prime}$ and $\omega$-phase using CALPHAD and artificial intelligence. Metals 2021, 11, 15. [CrossRef]

7. Jeong, W.; Shin, S.-E.; Choi, H. Microstructure and Mechanical Properties of Titanium-Equine Bone Biocomposites. Metals 2020, 10, 581. [CrossRef]

8. Meng, Q.; Li, H.; Wang, K.; Guo, S.; Wei, F.; Qi, J.; Sui, Y.; Shen, B.; Zhao, X. In situ synchrotron X-ray diffraction investigations of the nonlinear deformation behavior of a low modulus $\beta$-Type Ti36Nb5Zr alloy. Metals 2020, 10, 1619. [CrossRef]

9. Beltrán, V.; Weber, B.; Lillo, R.; Manzanares, M.-C.; Sanzana, C.; Fuentes, N.; Acuña-Mardones, P.; Valdivia-Gandur, I. Histomorphometric Analysis of Osseointegrated Grade V Titanium Mini Transitional Implants in Edentulous Mandible by Backscattered Scanning Electron Microscopy (BS-SEM). Metals 2021, 11, 2. [CrossRef] 